\title{
LIFE QUALITY OF EMPLOYEES OF THE NORTH-EASTERN FEDERAL UNIVERSITY (YAKUTSK)
}

DOI:10.36740/WLek202102109

\author{
Galina K. Stepanova, Maria V. Ustinova, Irina V. Nikolaeva \\ MK AMMOSOV NORTH-EASTERN FEDERAL UNIVERSITY, MEDICAL INSTITUTE, YAKUTSK, RUSSIA
}

\begin{abstract}
The aim of the study evaluate the quality of life of employees of the North Eastern Federal University.

Materials and methods: The respondents to the WHO QoL 100 questionnaire were 37 teachers and 32 support staff with an average age of 44 years.

Results and conclusions: There is a higher correlation between assessments of overall satisfaction with the quality of life and individual areas in the group of surveyed teachers compared to the group of support staff. Comparison of the parameters of the QOL areas of teachers of NEFU with the data of similar surveys of universities in Central Russia revealed a higher assessment of such areas as the "environment", the "physical" sphere among the Yakutia's. These results indicate the adaptability of NEFU employees to environmental conditions. Also, among the respondents of the Yakutia's, there was revealed a great significance for the $\mathrm{QO} \mathrm{L}$ of such a subsphere as support for relatives, friends and colleagues.
\end{abstract}

KEY WORDS: quality of life, WHO QoL-100 questionnaire, university staff, Yakutia

Wiad Lek. 2021;74(2):225-227

\section{INTRODUCTION}

Production of natural resources in the North is possible if people will settle there, which requires the improvement of the socio-economic living conditions and improving the quality of life (QoL). During 1991-2015 Yakutia lost almost 300 thousand people because of migration outflow [1]. The world health organization proposed to consider the quality of life as "the individual perception of his position in life in the context of the cultural environment and value system in which the individual lives, and in relation to his goals, expectations, standards and beliefs" [2]. The study of QoL of University teachers in Central Russia using international questionnaires WHOQ QoL-100, SV-36 was carried out in a number of papers $[3,4]$. However, the study of QoL in employees of the University, located in a region with uncomfortable natural conditions is of particular interest.

\section{THE AIM}

The aim of the study evaluate the quality of life of employees of the North Eastern Federal University.

\section{MATERIALS AND METHODS}

To study the quality of life, the basic questionnaire of quality of life ("WHOQ QoL-100") adapted for Russia at the research Institute of V. M. Bekhterev was used. The questionnaire includes 100 questions, and is a subjective scale (in points), designed to be filled by the Respondent. The scale of the questionnaire allows to assess the quality of 6 spheres of life: physical, psychological, spiritual sphere, the level of independence, social relationships and the environment. Each of the 6 spheres consists of subspheres, their total number is 24 . The quantitative characteristic of the total QoL is the sum of the values of all six spheres (the maximum value is 104.5 points). At the end of the questionnaire four global questions are included (G1-G4), the total score of answers to which $(\mathrm{G})$ allows you to give an integral assessment of the Respondent's satisfaction with the quality of life and health. Reduction of parameters of QoL testifies decreasing of general state of health and adaptive possibilities of an organism.

Two groups of female Yakut employees of NEFU were interviewed: the first group consisted of 37 people from the University professorial teaching staff (PTS) and the second group-32 people from the University training and support staff (TSS). Information was collected based on informed consent of respondents in compliance with the principles of bioethics. The average age of the University professorial teaching staff was 45.4 years, the University training and support staff was 42.4 years.

Statistical processing included the analysis of distributions, their proximity to the standard, finding the average values, the standard error of the average. The significance of the differences between the data of different groups was assessed using the Student's T-test. A correlation analysis of the relationship between the studied parameters was carried out.

\section{RESULTS AND DISCUSSION}

Differences of values of parameters of spheres of QoL between PTS and TSS are revealed (table 1). In the phys- 
Table I. Results of $\mathrm{Q} o \mathrm{~L}$ spheres in points $(\mathrm{M} \pm \mathrm{m}) \mathrm{NEFU}$ respondents

\begin{tabular}{cccc}
\hline Sphere & UTS & USS & P \\
\hline Phisical & $14.00 \pm 0.43$ & $12.82 \pm 0.43$ & 0.047 \\
\hline Psychological & $14.40 \pm 0,41$ & $12.55 \pm 0.45$ & 0.003 \\
\hline Level of independence & $16.13 \pm 0.66$ & $15.78 \pm 0.38$ & 0.706 \\
\hline Social relationships & $15.22 \pm 0.48$ & $14.20 \pm 0.46$ & 0.140 \\
\hline Environment & $13.26 \pm 0.32$ & $11.91 \pm 0.30$ & 0.002 \\
\hline Spiritual & $15.9 \pm 0.62$ & $14.12 \pm 0.54$ & 0.026 \\
\hline Total & $88.3 \pm 2.10$ & $80.5 \pm 2.00$ & 0.009 \\
\hline
\end{tabular}

Table II. Correlation coefficients between estimates of satisfaction with quality of life and individual areas of PTS (1) and TSS (2)

\begin{tabular}{cccccccccc}
\hline \multicolumn{10}{c}{ The life quality spheres } \\
\hline \multicolumn{2}{c}{ Environment } & \multicolumn{1}{c}{ Psychological } & \multicolumn{2}{c}{ Level of independence } & \multicolumn{2}{c}{ Physical } & Social relationships \\
\hline 1 & 2 & 1 & 2 & 1 & 2 & 1 & 2 & 1 \\
\hline 0.85 & 0.81 & 0.84 & 0.63 & 0.78 & 0.36 & 0.69 & 0.61 & 0.6 & 0.59 \\
\hline
\end{tabular}

ical sphere, QoL is significantly higher in the group of professorial teachers mainly due to the better indicator of the subsphere "sleep quality" compared to the training and support staff.

In the psychological sphere as a whole value of indicators at PTS are higher, than at TSS. In the components of this sphere concerning confidence, satisfaction with their abilities revealed a higher self-esteem of intellectual abilities memory, attention and learning. Significantly, higher rates were observed in PTS in the field of "environment". Thus, clearly expressed higher self-esteem in the subsphere of "Opportunities for the acquisition of new information and skills" in PTS ( $\mathrm{p}=0.002)$ opposite TSS, which may be associated with ongoing training courses for teachers. There is a tendency to a higher assessment of the quality and comfort of housing $(\mathrm{p}=0.07)$ in PTS $(15.5 \pm 0.66)$ relative to TSS $(13.7 \pm 0.82)$. PTS respondents also showed a tendency $(\mathrm{p}=0.01)$ to score higher in the "satisfaction with financial situation" sub-sphere $(11.0 \pm 0.68)$ compared to TSS (9.64 \pm 0.64$)$. Respondents in the PTS group had significantly higher rates in the spiritual sphere than in the TSS group. It is obvious that on the basis of the scientific worldview, PTS has formed more stable ideas about the meaning of life, which allow to resist the current life challenges. The indicator of the overall quality of life, calculated as the sum of the values of all six areas of the questionnaire, is significantly higher among PPS respondents, relative to TSS (table 1). It is necessary to note the large values of the total assessment of QoL in both groups of NEFU employees compared with teachers of the same age of Central Russian universities (74.4) [4].

The greatest differences between the teaching staff of Yakutsk and teachers of medical schools of Central Russia were in the assessment of the sphere "environment", respectively 13.26 and 9.69. The high rating of this sphere of the Yakuts may be due, on the one hand, adaptation to harsh climatic conditions, and the satisfaction with financial situation: payment of the regional factor and Northern extra charges, partially offsetting the uncomfortable living conditions in the North. Also, the Yakuts had a higher assessment of the sphere of "Social relations" (15.22) relative to the teaching staff of universities in Central Russia (13.14). It is obvious that in the harsh natural and climatic conditions of the Yakuts own QoL to a large extent associated with the support of relatives, friends and colleagues.

The study of correlations between the overall assessment of satisfaction with their QoL $(G)$ and indicators of individual areas is of interest. Positive correlations were found in both groups (table 2), which is consistent with the results of the study of QoL of University teachers in Central Russia [4]. The closest positive relationship of subjective assessment of QoL was revealed with the sphere of "environment" in both groups. The close relationship with the parameters of this sphere indicates that the subjective assessment of satisfaction with life expectancy is largely determined by the socio-economic status of respondents: income level, housing conditions, security of residence, medical care. For PTS higher values, in comparison with TSS, have indicators of the psychological sphere, including cognitive processes that allow teachers effectively perceive and process incoming information. PTS also attaches more importance to maintaining the "level of independence" of QoL compared to TSS (table 2). It is obvious that teachers appreciate the role of physical fitness in achieving high performance of their professional activities.

\section{CONCLUSIONS}

In conclusion, it should be noted that a comparative analysis of QoL in NEFU employees with different specifics of professional activity revealed a significantly higher final score in PPS relative to TSS. The most significant difference in responses between PPS and TSS was revealed in the areas of "Environment", "Psychological", "Spiritual". These areas were logically justified by higher grades in teaching staff on questions about the role of new information, self-as- 
sessment of intellectual abilities, the strength of ideological beliefs, that is, those components of life, which are most important in the professional activity of the teacher. Comparison of the parameters of QoL spheres with the data of teachers of universities of Central Russia [3] revealed a higher assessment of such spheres as "Environment", "Physical" spheres among the Yakuts. These results indicate the adaptation of NEFU PPS to environmental conditions. Also, the Yakut respondents revealed a great importance for the life of such a subsphere as the support of relatives, friends and colleagues.

Despite the difference in the indicators of various spheres of PPS and TSS, the integral subjective assessment of their own quality of life and health between the groups did not differ, which reflects the overall satisfaction with the situation of respondents in the social environment of the region.

\section{REFERENCES}

1. Sukneva S.A. The trend of migration dynamics in the Republic Sakha (Yakutia). Bulletin of the North-Eastern Federal University. Series: Sociology. 2013; 1: 31-40.

2. Study protocol for the World Health Organization project to develop a Quality of Life Assessment instrument. Quality of Life Research. 1993; 2: 153-158.

3. Kostakova T.A. Assessment of the quality of life of medical teachers Universities. Almanac of ModernScienceand Education. 2009;11 (1):140-141.
4. Tregubova E.S. Quality of life of teachers of medical universities. Public Health and Public Health. 2011; 1 (38): 17-21.

\section{ORCID and contributorship:}

Galina K. Stepanova: 0000-0001-5775-6528,D,F

Maria V. Ustinova: 0000-0002-9761-1064,C,E

Iryna V. Nikolaeva: 0000-0003-2478-69IX ${ }^{B, D, F}$

\section{Conflict of interest:}

The Authors declare no conflict of interest.

\section{CORRESPONDING AUTHOR \\ Galina K. Stepanova}

Medical institute, North-Eastern Federal University, Yakutsk, Russia tel: 89246612632

e-mail:g_k_step@mail.ru

Received: 17.12.2019

Accepted: 08.10.2020

A - Work concept and design, B - Data collection and analysis, C - Responsibility for statistical analysis, D-Writing the article, $\mathbf{E}$-Critical review, $\mathbf{F}$ - Final approval of the article 